\title{
The role of brain natriuretic peptides as a marker for diagnosing cardiac syncope: A narrative review
}

\author{
Hamideh Feiz Disfani ${ }^{1}$, Mostafa Kamandi ${ }^{2}{ }^{*}$, Kazem Rahmani ${ }^{3}$
}

${ }^{1}$ Assistant Professor of emergency medicine, department of emergency medicine, Mashhad University of medical sciences, Mashhad, Iran

${ }^{2}$ Fellowship of Hematology-Oncology, Department of Internal medicine, Mashhad University of medical sciences, Mashhad, Iran

${ }^{3}$ Student of Epidemiology, Department of Epidemiology and Biostatistics, Iran University of medical sciences, Tehran, Iran

\section{Correspondence}

Mostafa Kamandi, Fellowship of Hematology-Oncology, Department of Internal medicine, Mashhad University of medical sciences, Mashhad, Iran

Email: kazem3293@gmail.com

History

- Received: Oct 20, 2018

- Accepted: Nov 17, 2018

- Published: Dec 25, 2018

DOI :

https://doi.org/10.15419/bmrat.v5i12.509

\section{Check for updates}

\section{Copyright}

( ) Biomedpress. This is an openaccess article distributed under the terms of the Creative Commons Attribution 4.0 International license.

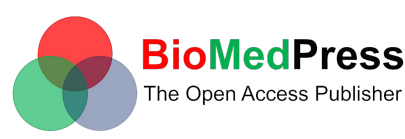

\begin{abstract}
Cardiac disease is the second common cause of syncope in emergency departments. Patients with Cardiac syncope have a higher risk of mortality than those who have a non-cardiac problem. Brain natriuretic peptide (BNP) as a cardiac marker has not thoroughly been evaluated in patients with syncope. This article focuses on the studies that have assessed BNP and NT-pro-BNP in cardiac and non-cardiac syncope patients in emergency departments.

Key words: Brain Natriuretic Peptide, Cardiac, Emergency departments, Syncope
\end{abstract}

\section{INTRODUCTION}

Syncope is defined as a temporary loss of consciousness followed by spontaneous and complete recovery ${ }^{1}$. In general populations, syncope is a common problem with the lifetime prevalence of $42 \%{ }^{2}$. It is estimated that $3 \%$ of referrals to emergency departments and $2 \%$ of inpatient admissions are due to syncope, and 6 out of 1000 people are affected by this problem every year ${ }^{3,4}$. Kapoor et al. published one of the first prospective syncope studies and showed that the risk of mortality due to syncope in a 12 -month follow-up was $14 \%{ }^{5}$. Serious underlying conditions such as dysrhythmia, structural heart disease, and significant hemorrhage can be the causes of syncope which ultimately lead to mortality and morbidity. The underlying conditions can be cardiac or vascular. The cardiac conditions are dysrhythmia and myocardial infarction (MI), and the vascular conditions are hemorrhage, aortic dissection, and pulmonary embolism ${ }^{6,7}$. The serum marker BNP which is increasingly established in emergency departments for the diagnosis of acute heart failure can reflect the presence of structural heart disease ${ }^{8-10}$. Many studies have stated that cardiac syncope is caused by reduced cardiac output that is associated with impaired hemodynamic in arrhythmia or structural cardiac disorders ${ }^{11}$. Therefore, brain natriuretic peptides are candidates for diagnosis of cardiac syncope. During the last decade, few studies were conducted to assess the role of BNP in isolating cardiac from non-cardiac syncope. This paper aimed to discuss the studies that evaluated the effect of brain natriuretic peptides on diagnosis and prediction of cardiac syncope in emergency departments.

\section{SYNCOPE RISK STRATIFICATION IN EMERGENCY DEPARTMENTS}

In risk stratification and diagnosis of syncope, we must consider three major issues addressed by Costantino et al. ${ }^{12}$ :

Differentiating patients with syncope from those with loss of consciousness of no syncopal source

According to the European Society of Cardiology (ESC) guidelines, syncope is defined as a transient loss of consciousness (T-LoC) caused by transient cerebral hypo-perfusion characterized by loss of consciousness followed by spontaneous and complete recovery $^{13}$. Therefore, syncope must be distinguished from T-LoC not induced by cerebral hypoperfusion Table 1.

\section{Distinguishing patients with syncope from those who have fallen}

Most of the time, distinguishing syncope from fall in clinical practice is impossible and exhausting. Taking a careful history from a witness plays a crucial role in facilitating the diagnosis during the early evaluation in the ED.

Determining how to manage patients presenting to the ED with near syncope or presyncope

Management of the pre-syncope and near syncope patients is largely heterogeneous worldwide at 
present $^{11,14}$. As Costantino et al. mentioned, presyncope or near syncope refers to the feeling of impending LoC without losing consciousness. Several symptoms and physical signs contribute to this feeling, such as weakness, tunnel vision, dizziness, nausea, sweating, and pallor.

Many studies performed in emergency departments exclude presyncope or near syncope because it is often assumed that these patients have a good prognosis. However, Grossman et al. compared the clinical outcomes of the patients with pre-syncope and the individuals with syncope, and no statistically significant difference was found between the two groups. They concluded that the prognosis of near syncope was similar to that of syncope.

\section{SYNCOPE RULES}

In emergency departments, many rules have been established to stratify the risk of a single patient presenting with syncope ${ }^{14}$. Examples of such rules are the San Francisco Syncope Rule (SFSR), Osservatorio Epidemiologico sulla Sincope nel Lazio (OESIL), Evaluation of Guidelines in Syncope Study (EGSYS), risk stratification of syncope in the emergency department (Rose), and Boston Syncope Rules. Among these rules, only SFRS had external validity in the systematic review by Saccilotto et al. ${ }^{15}$ with the sensitivity of $87 \%$ (95\%CI 79-93) and specificity of 52\% (95\% CI 43-62). One of these rules that considers the NTerminal pro-brain natriuretic peptide (NT-proBNP) and BNP is Rose published in 2010 and derived and validated in a single ED center in Edinburgh ${ }^{16}$. The follow-up time of this tool is 30 days, and it is utilized in clinical practices for better and more accurate diagnosis from BNP marker. The criteria for this diagnosis are as follows:

- BNP level $\geq 300 \mathrm{pg} / \mathrm{mL}$ or bradycardia $\leq 50$ in ED or pre-hospital

- Rectal examination showing fecal occult Blood (if suspicion of gastrointestinal Bleeding)

— Anemia: hemoglobin_90 g/L

- Chest pain

- ECG showing Q wave (not in the lead III)

$-\mathrm{O}_{2}$ Saturation $\leq 94 \%$ on room air

Patients are at high risk if a single variable is present.

The sensitivity and specificity for adverse events in this rule are $87 \%$ and $56 \%$, respectively ${ }^{16}$. Adverse events include pacemaker or cardiac defibrillator implant within 1 month from the index syncope, ventricular tachycardia, acute myocardial infarction, cerebrovascular accidents, life-threatening arrhythmias (ventricular fibrillation, sustained ventricular tachycardia [ $>120$ beats/min], ventricular pause $>3 \mathrm{sec}-$ onds), pulmonary embolism, intracranial or subarachnoid hemorrhage, hemorrhage requiring more than 2 units of blood transfusion, acute surgical procedures, or endoscopic intervention. These rules and biomarkers such as BNP, Troponin, and D-Dimer can diagnose most of the cardiac syncope patients from other types of syncope, and this issue is critical to decreasing the mortality and morbidity of syncope due to cardiac causes.

\section{DIAGNOSTIC VALUE OF BNP IN CHILDREN WITH SYNCOPE}

Syncope is a common problem in children and adolescents. A prevalence rate of $15 \%$ has been estimated for the syncopal episode in children under the age of $18^{21-23}$. Syncope in children and adolescents can be caused by underlying conditions. The most common type of syncope in children and adolescent is autonomic-mediated reflex syncope (AMS), resulted from the syncope caused by cardiac diseases ${ }^{17,24,25}$. About 1-3\% of children's and adolescents' admission in $\mathrm{ED}$ is associated with syncope (23-24). In our electronic search, we identified two studies on BNP value and syncope in children and adolescents. In a study by Wójtowicz J et al. ${ }^{24}$ who evaluated Natriuretic peptides in the children and adolescents with syncope, there was no significant difference in terms of BNP level between the syncope and control groups at all. Their study started with 88 and 25 participants in the syncope and control groups, respectively. The concentration of NT-proBNP in the syncope group was $24.5 \mathrm{pg} / \mathrm{mL}$, and that of NT-proBNP was $4.8 \mathrm{pg} / \mathrm{mL}$. In the control group, NT-proBNP and ANP concentrations were $25 \mathrm{pg} / \mathrm{mL}$ and $3 \mathrm{pg} / \mathrm{mL}$, respectively, which had no significant difference with the syncope group. Also, the children who were hospitalized due to syncope showed a significant difference in beats per min and a maximum heart rate during the 24-h electrocardiographic Holter monitoring. In another study, Zhang Q et al. ${ }^{25}$ evaluated "Diagnostic value of serum brain natriuretic peptide in syncope in children and adolescents." The study concluded that Serum BNP was helpful in differentiating cardiac syncope from non-cardiac syncope in children and adolescents. Sixty-two children and adolescents admitted in ED for syncope were evaluated, among whom 23 participants had cardiac syncope, and 39 had non-cardiac syncope. Regarding BNP levels, there was a significant difference between cardiac syncope $(958.78 \pm 2443.41 \mathrm{pg} / \mathrm{mL})$ and noncardiac syncope $(31.05 \pm 22.64 \mathrm{pg} / \mathrm{mL})$ groups $(\mathrm{P}$ value $<0.05)$. Furthermore, a significant difference 


\begin{tabular}{ll}
\hline Table 1: Life threatening disorders leading & to syncope with cardiovascular source \\
\hline Arrhythmias & Ventricular tachycardia \\
& Bradycardia: Mobitz type II or third degree \\
& heart block \\
& Significant sinus pause (>3 seconds) \\
& Long QT syndrome \\
& Brugada syndrome \\
ECG features & Acute coronary syndrome, myocardial \\
& infarction \\
& Valvular heart disease: aortic stenosis/mitral stenosis \\
Ischemia & Cardiomyopathy (ischemic, dilated ,hypertrophic) \\
Structural abnormalities & Atrial myxoma \\
& Cardiac tamponade \\
& Aortic dissection \\
& Trauma with significant blood loss \\
Gignificant hemorrhage & Tissue rupture: aortic aneurysm, spleen/ovarian cyst, ectopic pregnancy \\
Pulmonary embolism & Sadroperitoneal hemorrhage \\
& obstruction or severe hypoxia \\
& \\
&
\end{tabular}

was observed in terms of mean age, number of predisposing factors during exercise, number of prodromal symptoms and number of Standard ECG abnormalities. The Hypertrophic cardiomyopathy and Cardiac arrhythmia had maximum and minimum values of BNP, respectively $(2873.88 \pm 4378.15 \mathrm{pg} / \mathrm{mL}$ and $46.83 \pm 25.63 \mathrm{pg} / \mathrm{mL}$ ). Other aspects of these studies are presented in Table 2.

\section{DIAGNOSTIC VALUE OF BNP IN ADULTS WITH SYNCOPE}

In the electronic search strategy, six studies were identified in which the inclusion criterion was adult syncope. Summaries of these studies are shown in Table 2. A significant difference was found between the mean ages in cardiac syncope compared to noncardiac syncope in four studies. In the cardiac syncope groups, age was higher than in the non-cardiac syncope ones, and the cause of this relationship was unclear. The results of these studies showed that measuring the BNP level in EDs was very helpful for diagnosis of the individuals with cardiac syncope, and decreased the chance of mortality due to cardiac syncope by using guidelines or rules. Tanimoto $\mathrm{K}$ et al. ${ }^{17}$ studied BNP for separating cardiac and non-cardiac syncope, and considered the cut-off value of $40 \mathrm{pg} / \mathrm{ml}$ for isolating cardiac and non-cardiac syncope with $82 \%$ sensitivity and $92 \%$ specificity for identification of cardiac syncope. The authors of this study concluded that a significant relationship was found in terms of BNP level between the cardiac group $(118 \pm 42 \mathrm{pg} / \mathrm{ml})$ and those in the other three groups (Reflex-mediated, Neurologic, and Unknown). Pfister et al. ${ }^{8}$ showed that the assessment of NT-pro-BNP was helpful in differentiating cardiac from non-cardiac syncope. A significant difference was observed in BNP level for cardiac group compared to the non-cardiac one (514 $\mathrm{pg} / \mathrm{ml}$ vs. $182 \mathrm{pg} / \mathrm{ml}, \mathrm{P}$-value $<0.05)$. The authors of this study also concluded that the NT-pro-BNP had a high sensitivity and a high negative predictive value for the cardiac cause in patients with syncope and was a better predictor than clinical and ECG features.

\section{CONCLUSION}

We concluded that a biochemical marker such as BNP and other forms of this marker was very helpful in separating and diagnosing cardiac syncope patients and predicting their mortality. This marker, as well as other ones, seem to be very helpful in emergency departments. The accuracy and precision of diagnosing and predicting prognosis of cardiac syncope with 


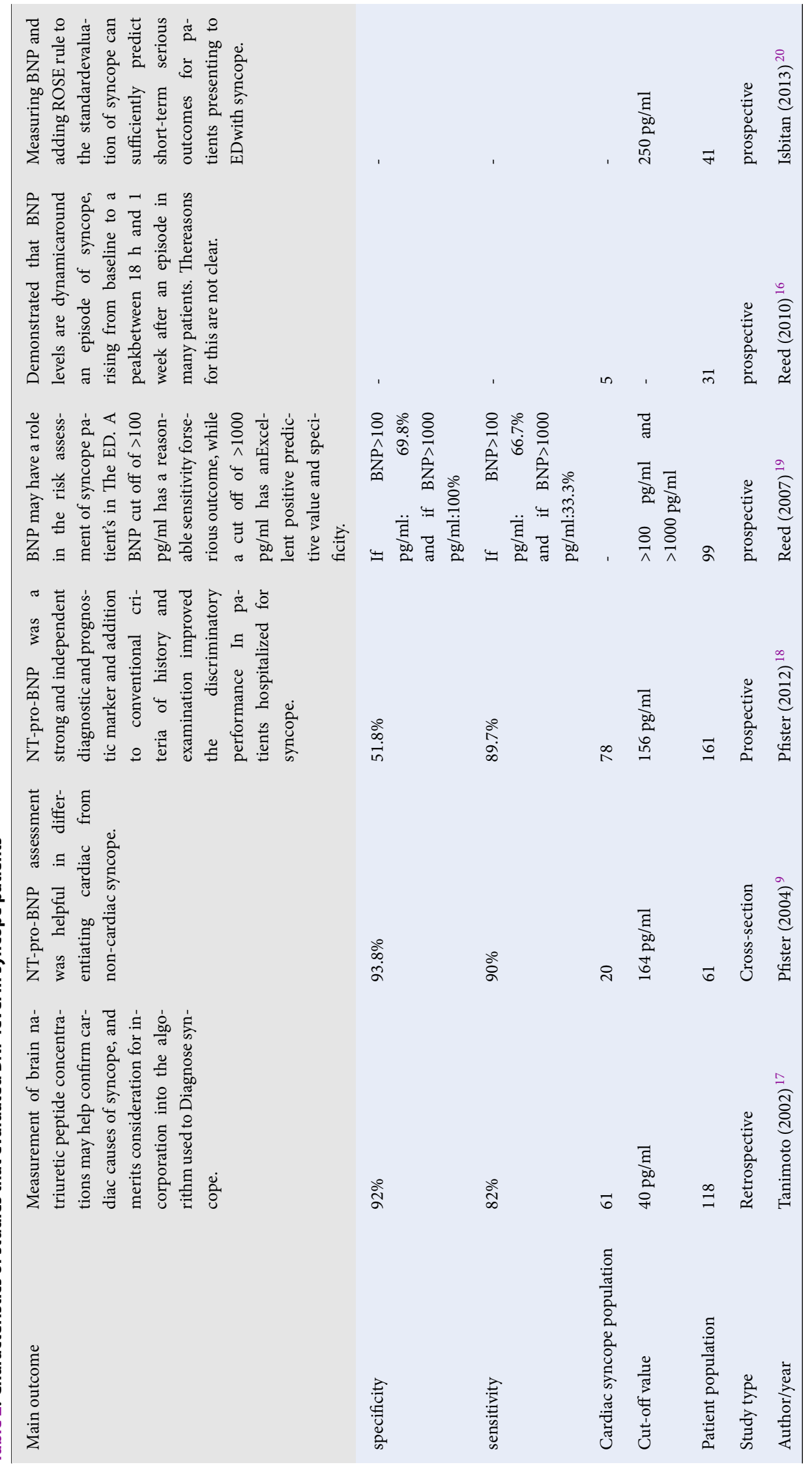


Rules were increased. There are few studies on syncope in children, and more studies need to be conducted to clarify the causal relationship.

\section{RECOMMENDATIONS AND FUTURE STUDIES}

According to some of the recommendations in previous studies, more research is needed to be conducted to clarify this relationship and the variables that might play the role of confounders in a causal inference. More studies are required on children because there is some controversy in this relationship. And finally, we suggest to study syncope patients with large sample sizes and randomized control trial studies to ensure that this marker is helpful in recognizing and predicting the prognosis of the disease.

\section{ABBREVIATIONS}

AMS: autonomic-mediated reflex syncope

BNP: Brain Natriuretic Peptides

ECG: electrocardiography

ED: Emergency Department

EGSYS: Evaluation of Guidelines in Syncope Study

ESC: European Society of Cardiology

MI: myocardial infarction

NT-proBNP: N-Terminal pro-brain natriuretic peptide

OESIL: Osservatorio Epidemiologico sulla Sincope nel Lazio

Rose: risk stratification of syncope in the emergency department

SFSR: San Francisco Syncope Rule

\section{COMPETING INTERESTS}

The authors report no conflicts of interest in this work.

\section{AUTHORS' CONTRIBUTIONS}

Hamideh Feiz Disfani proposed and designed the study, Mostafa Kamani collected the Data and managing manuscripts, Kazem Rahmani contributed in writing and approving the study.

\section{REFERENCES}

1. Brignole M, Alboni P, Benditt D, Bergfeldt L, Blanc JJ, Thomsen PEB, et al. Guidelines on management (diagnosis and treatment) of syncope. European Heart Journal. 2001;22:1256306. Available from: DOI:10.1053/euhj.2001.2739.

2. Soteriades ES, Evans JC, Larson MG, Chen MH, Chen L, Benjamin EJ. Incidence and prognosis of syncope. The New England Journal of Medicine. 2002;347:878-85. Available from: DOI:10.1056/NEJMoa012407.

3. Maisel WH, Stevenson WG. Syncope-getting to the heart of the matter; 2002. Available from: DOI:10.1056/NEJMe020102.

4. Disfani HF, Kamandi M, Rahmani K. Brain Natriuretic Peptides in Screening of Syncope with Cardiac Origin; a Commentary. Emergency (Tehran, Iran). 2018;6.
5. Kapoor WN, Karpf M, Wieand S, Peterson JR, Levey GS. A prospective evaluation and follow-up of patients with syncope. The New England Journal of Medicine. 1983;309:197204. Available from: Doi:10.1056/nejm198307283090401.

6. Thiruganasambandamoorthy V, Hess EP, Turko E, Perry JJ, Wells GA, Stiell IG. Outcomes in Canadian emergency department syncope patients-are we doing a good job? The Journal of Emergency Medicine. 2013;44:321-8. Available from: DOI:10.1016/j.jemermed.2012.06.028.

7. Fonarow GC, Peacock WF, Phillips CO, Givertz MM, Lopatin $\mathrm{M}$, Committee AS, et al. Admission B-type natriuretic peptide levels and in-hospital mortality in acute decompensated heart failure. Journal of the American College of Cardiology. 2007;49:1943-50. Available from: DOI:10.1016/j.jacc.2007.02. 037.

8. Pfister R, Tan D, Thekkanal J, Hellmich M, Schneider CA. Predictors of elevated NT-pro-BNP in cardiovascular patients without acute heart failure. International Journal of Cardiology. 2009;131:277-80. Available from: DOI:10.1016/j.ijcard.2007. 07.047 .

9. Pfister R, Scholz M, Wielckens K, Erdmann E, Schneider CA. Use of NT-proBNP in routine testing and comparison to BNP. European Journal of Heart Failure. 2004;6:289-93. Available from: DOI:10.1016/j.ejheart.2003.12.012.

10. Tada H, Ito S, Shinbo G, Tadokoro K, Ito I, Hashimoto T. Significance and utility of plasma brain natriuretic peptide concentrations in patients with idiopathic ventricular arrhythmias. Pacing and Clinical Electrophysiology. 2006;29:1395403. Available from: DOI:10.1111/j.1540-8159.2006.00553.x.

11. Sun BC, Thiruganasambandamoorthy V, Cruz JD, to Standardize EDSRSRC. Standardized reporting guidelines for emergency department syncope risk-stratification research. Academic Emergency Medicine. 2012;19:694-702. Available from: DOI:10.1111/j.1553-2712.2012.01375.x.

12. Costantino G, Furlan R. Syncope risk stratification in the emergency department. Cardiology Clinics. 2013;31:27-38. Available from: DOI:10.1016/j.ccl.2012.10.003.

13. Moya A, Sutton R, Ammirati F, Blanc JJ, Brignole M, Dahm JB, et al. Guidelines for the diagnosis and management of syncope (version 2009). European Heart Journal. 2009;30:263171. Available from: DOI:10.1093/eurheartj/ehp298.

14. Grossman SA, Babineau M, Burke L, Kancharla A, Mottley L, Nencioni A. Do outcomes of near syncope parallel syncope? The American Journal of Emergency Medicine. 2012;30:2036. Available from: DOI:10.1016/j.ajem.2010.11.001.

15. Saccilotto RT, Nickel CH, Bucher HC, Steyerberg EW, Bingisser R, Koller MT. San Francisco Syncope Rule to predict short-term serious outcomes: a systematic review. Canadian Medical Association Journal. 2011;183:E1116-E1126. Available from: 10.1503/cmaj.101326.

16. Reed MJ, Newby DE, Coull AJ, Prescott RJ, Jacques KG, Gray AJ. The ROSE (risk stratification of syncope in the emergency department) study. Journal of the American College of Cardiology. 2010;55:713-21. Available from: DOI:10.1016/j.jacc. 2009.09.049.

17. Tanimoto $\mathrm{K}$, Yukiiri $\mathrm{K}$, Mizushige $\mathrm{K}$, Takagi $\mathrm{Y}$, Masugata $\mathrm{H}$, Shinomiya $\mathrm{K}$. Usefulness of brain natriuretic peptide as a marke for separating cardiac and noncardiac causes of syncope. The American Journal of Cardiology. 2004;93:228-30. Available from: DOI:10.1016/j.amjcard.2003.09.048.

18. Pfister R, Tan D, Thekkanal J, Hellmich M, Schneider CA. Predic tors of elevated NT-pro-BNP in cardiovascular patients without acute heart failure. International journal of cardiology. 2009;131(2):277-280.

19. Reed MJ, Newby DE, Coull AJ, Jacques KG, Prescott RJ, Gray AJ. Role of brain natriuretic peptide (BNP) in risk stratification of adult syncope. Emergency Medicine Journal. 2007:24(11):769-773.

20. Isbitan A, Hawatmeh A, Elnahar Y, Patel K, Altheeb Z, Debari V et al. Utility of brain natriuretic peptide assay as a predictor of short term outcomes in patients presenting with syncope to the emergency department. Cardiovascular diagnosis and therapy. 2016;6(3):234 
21. Driscoll DJ, Jacobsen SJ, Porter CJ, Wollan PC. Syncope in children and adolescents. Journal of the American College of Cardiology. 1997;29:1039-45. Available from: Doi:10.1016/s07351097(97)00020-x.

22. Massin MM, Bourguignont A, Coremans C, Comte L, Lepage $P$, Gerard P. Syncope in pediatric patients presenting to an emergency department. The Journal of Pediatrics. 2004;145:223-8. Available from: DOI:10.1016/j.jpeds.2004.01.048.

23. Wieling W, Ganzeboom KS, Saul JP. Reflex syncope in children and adolescents. Heart (British Cardiac Society). 2004;90:1094-100. Available from: DOI:10.1136/hrt.2003.
022996.

24. Wojtowicz J, Szczepanski W, Bogdan A, Baran M, Szczurak J, Bossowski A. Natriuretic peptides in the evaluation of syncope in children and adolescents. Scandinavian Journal of Clinical and Laboratory Investigation. 2014;74:301-5. Available from: Doi:10.3109/00365513.2014.883550.

25. Zhang Q, Jin H, Qi J, Yan H, Du J. Diagnostic value of serum brain natriuretic peptide in syncope in children and adolescents. Acta Paediatrica (Oslo, Norway). 2013;102:e210-4. Available from: DOI:10.1111/apa.12182. 